\title{
Influence of the Treatment Phase on the Gluing Performance of Glued Laminated Timber
}

\begin{abstract}
André M. A. Dias, * Carlos E. J. Martins, and Alfredo M. P. G. Dias
Glued laminated timber (glulam) is a wood-based product with frequent use in timber construction. Maritime pine (Pinus pinaster Ait.) is a species suitable for glulam production and is available with abundance in Portuguese forests. This study assessed the influence of the phase in which the preservative treatment is applied in the surface bonding performance. Several elements were produced considering different treatment scenarios: timber without treatment, timber treated before gluing, and timber treated after gluing. The bonding quality was tested by both shear strength and delamination tests, following the indications given in EN 14080 (2013). Glulam elements treated after gluing (TAG) presented less delamination when compared with the ones treated before gluing (TBG). However, TBG elements presented higher shear strength values than TAG elements. Despite the recorded differences, all the considered sets performed adequately both for delamination and shear strength tests.
\end{abstract}

Keywords: Pinus pinaster Ait.; Glued Laminated Timber; Preservative treatment; Delamination; Shear strength

Contact information: ISISE, Department of Civil Engineering, University of Coimbra, R. Luis Reis dos Santos 290, 3030-790 Coimbra, Portugal; *Corresponding author: andre.dias@ student.dec.uc.pt

\section{INTRODUCTION}

Timber has been used for structural applications since the beginning of humankind, and significant advances have been observed in its use for indoor applications and, in recent decades, more often for outdoor applications. However, there are some important limitations, such as the susceptibility to decay, which significantly affects the performance of the structures and in many cases is the cause of failures and malfunction (Freeman et al. 2003). There are different approaches to mitigate this problem; chemical preservative treatments are some of the most effective.

Most species used for glulam are slightly/moderately durable to fungi attack and susceptible to termites or Hylotrupes bajulus attacks, as measured by EN 350-2 (1994). The consideration of preservative products is an alternative to improve the low natural durability of species such as maritime pine.

According to Nunes et al. (2016), carbolineum (anthracene oil) was the first preservative product used in Portugal as early as 1900. For applications in exposed conditions, mainly railway sleepers, telephone and telegraph poles, preservatives such as copper naphthalene and pentachlorophenol were used and later replaced with creosote, chromated copper arsenate (CCA), chromated copper borate (CCB), and other products (Nunes et al. 2016). 
Since 2000, the European Union has approved new regulations with specific restrictions on preservative products that have been used in Europe for many years, including creosote, CCA, and CCB (Coggins 2008). New organic preservative products were developed based on copper. TANALITH E and CELCURE are the most common ones in Portugal, as reported by 23 companies from a total of 33 production plants with an autoclave installed for preservation by impregnation (Nunes et al. 2016).

Glulam is one of the most used engineered wood products. However, its application in exterior conditions (Service Class 3) requires the adoption of protecting measures such as coatings. The bonding performance of preservative-treated wood has been examined for decades, considering several wood species, adhesives, and preservative products (Truax et al. 1953; Selbo 1957, 1959; Raknes 1963; Miyazaki and Nakano 2003). The use of primers was also considered to improve the resistance to delamination by Vick $(1995,1997)$ and Lorenz and Frihart (2006).

Maritime pine is the dominant softwood species in the Portuguese National Forest and has been considered for glulam production in previous studies (Costa 1978; Cruz 1985; Sousa 1990); it is one of the species covered by EN 14080 (2013). Maritime pine can be impregnated and therefore is a good alternative for uses in Service Class 3 (Use Classes 3 or 4). Gaspar et al. (2009) assessed the bonding performance on maritime pine preservative treated with TANALITH E 3492 glued with PRF adhesive, confirming the good bonding performance through delamination and shear strength tests. The delamination was always higher than in untreated wood. However, the bonding performance of preservative-treated maritime pine in the natural ageing process revealed inadequate performance after 9 months of exposure. The bonding performance of maritime pine (untreated and preservative treated) glued with primer solutions has been tested. Lampreia (2010) carried out a study to assess the influence of using a hydroxymethylated resorcinol (HMR) based primer on the bonding performance of treated maritime pine with TANALITH E 3492 and TANALITH E NB. However, the PRF adhesive (resin - Prefere 4040 and hardener Prefere 5839) showed an adequate bonding performance even without the use of primer and for both preservative products.

Silva (2010) investigated the delamination performance of railway sleepers in two conditions: untreated timber and timber treated with creosote after bonding (Use Class 4). Scots pine (Pinus sylvestris L.) and maritime pine (non-structural elements) were glued with two types of adhesives (PRF and MUF). The authors observed that the delamination was higher within the specimens tested after treatment, being approximately $35 \%$ and $60 \%$ higher for maritime pine (PRF and MUF, respectively). For Scots pine, the difference was even higher (> 3 times) despite the lower average values of delamination $(1.8 \%$ for untreated and $5.9 \%$ for preservative-treated) compared to maritime pine $(6.3 \%$ untreated and $10.1 \%$ preservative-treated), both glued with MUF adhesive.

Several studies have evaluated the bonding performance of glued preservativetreated wood, in some cases mentioning the advantages and disadvantages of applying the treatment before or after gluing. Despite that, there have been no studies that have compared the effect of the treatment phase (before and after bonded) on bonding performance of glulam. Treated maritime pine is a good alternative for other European softwoods in glulam production. This study assessed the surface bonding quality of glulam elements treated before or after gluing with the TANALITH E 8001 product. 


\section{EXPERIMENTAL}

\section{Materials}

Two samples of maritime pine were considered: i) untreated boards (S1) and preservative treated boards with TANALITH E 8001 (S2). Each board was weighed and measured in its cross-sectional dimensions and length to determine its density. S1 had a nominal density at $12 \%$ moisture content of $623 \pm 50 \mathrm{~kg} / \mathrm{m}^{3}$, whereas $\mathrm{S} 2$ had $638 \pm 46 \mathrm{~kg} / \mathrm{m}^{3}$. The timber boards of both samples had the nominal dimensions of $40 \mathrm{x}$ $110 \times 2500 \mathrm{~mm}^{3}$. The moisture content of each board was measured with an electrical moisture meter according to EN 14080, Annex G (2013), resulting in a mean value of $13.1 \pm 0.8 \%$ for sample $\mathrm{S} 1$ and $17.8 \pm 1.4 \%$ for sample $\mathrm{S} 2$.

TANALITH E 8001 (Lonza, 2020) is a commercial water-based product for wood preservative treatment by impregnation and is composed of copper and organic biocides. The composition of TANALITH E 8001 product is presented in Table 1.

Table 1. TANALITH E 8001 - Active Compounds and Quantities

\begin{tabular}{|c|c|}
\hline Element & Amount $(\% \mathrm{~m} / \mathrm{m})$ \\
\hline Copper carbonate & $14.55(8 \% \mathrm{Cu})$ \\
\hline Tebuconazole & 0.16 \\
\hline Propiconazole & 0.16 \\
\hline Didecyldimethylammonium chloride [DDAC] & 0.50 \\
\hline
\end{tabular}

The gluing process was done with two commercial adhesives of type I, namely, phenol-resorcinol formaldehyde (PRF) and melamine-urea-formaldehyde (MUF). The adhesive mixture of both adhesives was based in a ratio resin/hardener of 100/20.

The PRF adhesive was considered previously on untreated and preservative-treated maritime pine glulam (Lampreia 2010). According to Jiang et al. (2014), a decrease in the use of PRF adhesives was noticed due to its brown colour. MUF adhesives are interesting alternatives due to their white colour. There are no previous tests performed on maritime pine glulam glued with MUF adhesives that ensure its performance in delamination and shear strength tests. For both adhesives, the technical data sheets (TDS) were considered to define the amount of adhesive, clamping pressure, and pressing time used for the assembly process.

\section{Glulam Elements Production}

To achieve the intended objectives, three different gluing sets were considered: i) glulam elements of untreated boards (MP); ii) glulam elements from preservative-treated boards (TBG); and iii) glulam elements from untreated boards and treated by impregnation after the gluing process (TAG). These sets were considered for both adhesives. In total, 22 elements were produced in a laboratory: 6 elements for MP set ( 3 per adhesive), 8 elements for TBG set (4 per adhesive), and 8 elements for TAG set (4 per adhesive). Each element comprised 4 lamellas of $30 \mathrm{~mm}$ of thickness and $1 \mathrm{~m}$ length. The final cross-section after planing was approximately $110 \mathrm{~mm}$ in width and $120 \mathrm{~mm}$ in height.

\section{Planning, assembly and pressure}

The production of all glulam elements began with the planing of the boards to the final thickness $(30 \mathrm{~mm})$. The adhesive mixture was prepared immediately before being 
applied in one surface of adjacent lamellas. A manual spreader was used to uniformly distribute the adhesive, which was the amount applied controlled by weighing. The amount of adhesive considered was the value in between the interval defined in the TDS of the adhesive, which was $350 \mathrm{~g} / \mathrm{m}^{2}$ for PRF adhesive and $400 \mathrm{~g} / \mathrm{m}^{2}$ for MUF adhesive.

The clamping pressure was based on the results of Cruz et al. (2018) for untreated maritime pine glulam elements and within the interval defined in EN 14080 (2013) for softwoods. The values of 0.8 and $0.6 \mathrm{MPa}$ were adopted for clamping pressure for the PRF and MUF adhesives, respectively. The pressing time considered followed the TDS of each adhesive, namely $240 \mathrm{~min}$ for PRF and $540 \mathrm{~min}$ for MUF. The assembly was performed in controlled conditions $\left(20{ }^{\circ} \mathrm{C}\right.$ and $65 \%$ relative humidity), and after that, the glulam elements were kept in the controlled conditions to ensure the curing process of the adhesives for at least 7 days.

\section{Treatment process}

From the assembly process, 22 glulam elements were obtained (14 made from untreated maritime pine and 8 from preservative-treated maritime pine). The preservative product considered for the sample S2 was the TANALITH E 8001. From the 14 untreated glulam elements, 8 of them were subjected to the treatment process with the referred treatment product used in sample $\mathrm{S} 2$ (TAG).

The treatment process was based on the full-cell process, which is also designated as the Bethell Process. The treatment was applied to place the timber in a pressure vessel and adding the treatment product diluted with water. The impregnation of the preservative product in the wood was made applying consecutive cycles of vacuum and pressure in a vessel. Both glulam elements of TBG and TAG were submitted to identical treatment with the same preservative product. The product retention was approximately $31 \mathrm{~kg} / \mathrm{m}^{3}$, which met the requirements of Use Class 4 and consequently the use of the elements under Service Class 3.

After the treatment process, the glulam elements from TAG set were stored in outdoor conditions for 2 weeks, and the moisture content was estimated based on the initial moisture content (determined based on the average moisture content of lamellas), the weight before being treated, and the retention of the product within the treatment process. The estimated moisture content of all glulam beams was higher than $18 \%$, and it was decided to dry the elements in a climatic chamber with controlled conditions of temperature and relative humidity to dry the glulam elements to moisture contents closer to $12 \%$. The temperatures and relative humidity were defined to achieve an equilibrium moisture content of 10 to $12 \%$ (USDA 2010). During the drying process, the elements were weighed, and the estimated moisture content was determined. After 28 days, 7 in 8 elements had an estimated average moisture content of $13.3 \%$, and only one element (TAG_PRF_1) had an estimated value of $21.2 \%$.

\section{Test Methods}

The bonding quality of all glued elements manufactured in this study was assessed through delamination and shear strength tests, following the specifications of EN 14080 (2013). For the delamination tests, a total of 7 specimens per glulam element were obtained and tested. In relation to shear strength tests, 14 specimens were obtained from each glulam element being divided by glue line tests ( 10 specimens per glulam element) and lamellae tests (4 specimens per glulam element). The number of delamination and shear specimens and tests per set is given in Table 2. 
Table 2. Number of Delamination and Shear Specimens and Tests Per Set

\begin{tabular}{|c|c|c|c|c|c|c|c|}
\hline \multirow{2}{*}{\multicolumn{2}{|c|}{$\begin{array}{c}\text { Sample of wood } \\
\text { Glulam set }\end{array}$}} & \multicolumn{4}{|c|}{ Untreated Maritime pine } & \multirow{2}{*}{\multicolumn{2}{|c|}{$\begin{array}{c}\text { Treated Maritime pine } \\
\text { TBG }\end{array}$}} \\
\hline & & \multicolumn{2}{|c|}{ MP } & \multicolumn{2}{|c|}{ TAG } & & \\
\hline \multicolumn{2}{|c|}{ Type of adhesive } & PRF & MUF & PRF & MUF & PRF & MUF \\
\hline \multicolumn{2}{|c|}{ No. of glulam elements } & 3 & 3 & 4 & 4 & 4 & 4 \\
\hline \multicolumn{2}{|c|}{$\begin{array}{l}\text { No. of delamination specimens / } \\
\text { tests }\end{array}$} & $21 / 21$ & $21 / 21$ & $28 / 28$ & $28 / 28$ & $28 / 28$ & 28 / 28 \\
\hline \multicolumn{2}{|c|}{ No. of shear specimens } & 42 & 42 & 56 & 56 & 56 & 56 \\
\hline \multirow{2}{*}{ No. of shear tests } & Glue line & 90 & 90 & 120 & 120 & 120 & 120 \\
\hline & Lamellae & 48 & 48 & 64 & 64 & 64 & 64 \\
\hline
\end{tabular}

\section{Delamination tests}

Delamination tests consist of the introduction of a moisture gradient into the specimens, which causes internal stresses perpendicular to the glue lines. The test protocol followed the specifications of Annex C of EN 14080 (2013). From Annex C, two methods (Method A and Method B) could be considered to assess the bonding quality of glued elements intended to be used in Service Class 3. Based on previous studies performed with maritime pine (untreated and preservative treated), Method A was used. The delamination was measured at the end of $2^{\text {nd }}$ and $3^{\text {rd }}$ cycle, and the total delamination and maximum delamination were determined.

As the treatment penetration is higher in fibers direction, the specimens can be sealed during the delamination tests, as reported by Li et al. (2018). The sealing prevents moisture transfer in the direction of the fibers. To ensure the comparability of delamination tests results with literature results for maritime pine, the wood elements were not sealed.

\section{Shear strength tests}

Shear strength tests are based on loading consecutive lamellas in such a way that shear stresses are introduced in the glue lines until the failure occurs. For each specimen 3 glue lines were tested. It was also considered to perform shear tests in lamellas to assess the efficiency of the glue line, with 4 tests being performed per specimen. The test procedure is indicated by Annex D of EN 14080 (2013).

A constant rate of displacement of $0.006 \mathrm{~mm} / \mathrm{s}$ was considered. After each test, the wood failure percentage (WFP) and the maximum load were recorded. To easily identify the failure by wood, a mixture (50/50) of phloroglucinol (2\%) with chloridric acid solution $(10 \%)$ was used to highlight the lignin of wood and distinguish the failure within the wood from the failure within the adhesive.

\section{RESULTS AND DISCUSSION}

\section{Delamination and Shear Strength Tests}

The results from delamination tests are presented in Table 3 for both PRF and MUF adhesives. For each treatment phase, and for both test cycles, the mean values of total delamination are presented, together with the mean of maximum delamination values. The maximum values registered by set are presented in brackets. Figure 1 presents the shear 
strength results for each glue line test and the respective wood failure percentage (WFP) for each treatment phase and adhesive considered.

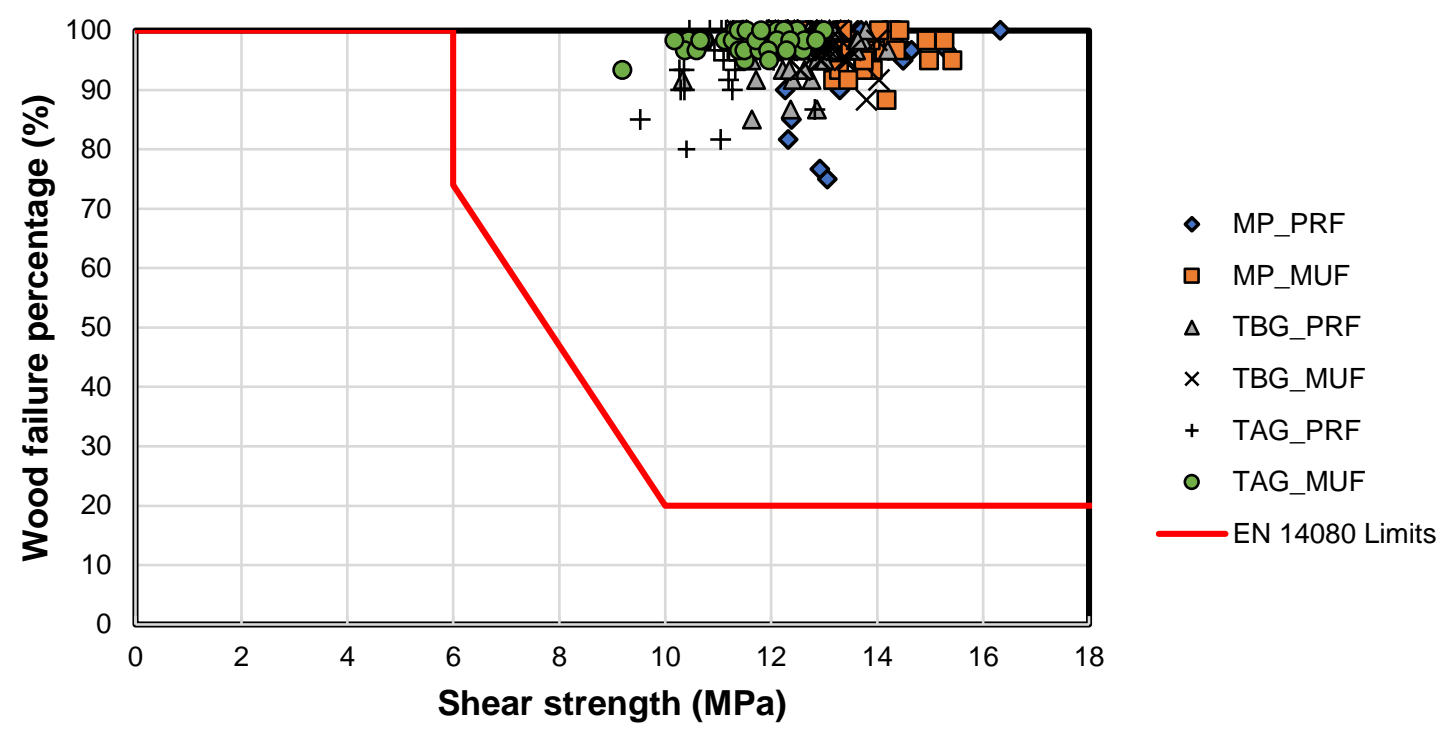

Fig. 1. Shear strength and wood failure percentage - individual values

In terms of total delamination, both adhesives showed a good performance in terms of mean values, with slightly higher values observed with MUF adhesive for TBG set. As expected, an increase of values was recorded from the $2^{\text {nd }}$ cycle to the $3^{\text {rd }}$ cycle. Some TBG specimens presented higher total delamination than the established limits given in EN $14080(2013)\left(5 \%-2^{\text {nd }}\right.$ cycle and $10 \%-3^{\text {rd }}$ cycle $)$. All the glue lines had a maximum delamination lower than the limit of 30\% proposed by EN 14080 (2013).

The individual values of glue line shear strength and WFP showed adequate performance ensured by both adhesives, with all tests fulfilling the minimum limits established by the standard (minimum of $4 \mathrm{MPa}$ if the WFP is $100 \%$ ). However, the PRF glue lines had lower WFP than glue lines of MUF, and the glue lines of the TAG set had lower shear strength when compared with TBG and MP.

\section{Influence of Treatment Phase}

The influence of treatment phase was assessed by comparing the delamination and shear strength results per treatment set and adhesive. The boxplot methodology was used for the comparison of delamination results after the $3^{\text {rd }}$ test cycle (Fig. 2). From the PRF adhesive results, similar values were found between MP and TAG elements. Slightly higher delamination values were found within TBG elements being negligible the negative effect of the preservative treatment applied before gluing, as observed by Lampreia (2010).

However, elements glued with MUF adhesive were clearly not influenced by the application of preservative treatment after the gluing process (TAG), presenting slightly lower values on delamination compared to MP set. On the opposite way, the elements that were treated before gluing (TBG) had a significant increase in total delamination (mean values). Excessive delamination (higher than 10\%) was registered in 4 specimens (from a total of 28) after the $3^{\text {rd }}$ test cycle of TBG_MUF specimens. A detailed analysis showed that the 4 specimens with excessive total delamination belonged to the same glued element. 
Table 3. Summary of Total Delamination (Mean Values) and Maximum Delamination (Mean Values) After Both Test Cycles of Delamination - PRF and MUF Adhesives

\begin{tabular}{|c|c|c|c|c|c|}
\hline \multicolumn{2}{|c|}{ Adhesive: PRF } & \multicolumn{2}{|c|}{$2^{\text {nd }}$ Cycle } & \multicolumn{2}{|c|}{$3^{\text {rd }}$ Cycle } \\
\hline & No. specimens & Total delam. (\%) & Max delam. (\%) & Total delam. (\%) & Max delam. (\%) \\
\hline MP & 21 & 0.89 (3.51) & $2.52(9.02)$ & 1.07 (3.51) & $2.88(9.16)$ \\
\hline TBG & 28 & $1.21(5.97) * 1$ & $2.79(12.44)$ & $1.67(7.52)$ & $3.70(13.31)$ \\
\hline TAG & 28 & 0.95 (3.69) & $2.22(7.48)$ & $1.28(3.96)$ & $2.91(8.67)$ \\
\hline \multicolumn{2}{|c|}{ Adhesive: MUF } & \multicolumn{2}{|c|}{$2^{\text {nd }}$ Cycle } & \multicolumn{2}{|c|}{$3^{\text {rd }}$ Cycle } \\
\hline & No. specimens & Total delam. (\%) & Max delam. (\%) & Total delam. (\%) & Max delam. (\%) \\
\hline MP & 21 & $0.84(3.32)$ & $2.23(9.95)$ & $0.99(3.56)$ & $2.61(10.51)$ \\
\hline TBG & 28 & $3.02(11.37) * 8$ & $6.18(20.89)$ & $3.52(12.81)^{* 4}$ & 7.01 (23.31) \\
\hline TAG & 28 & $0.54(2.31)$ & $1.38(6.90)$ & $0.71(2.91)$ & $1.74(8.34)$ \\
\hline
\end{tabular}

Note: Parentheses indicate the maximum value for each set 


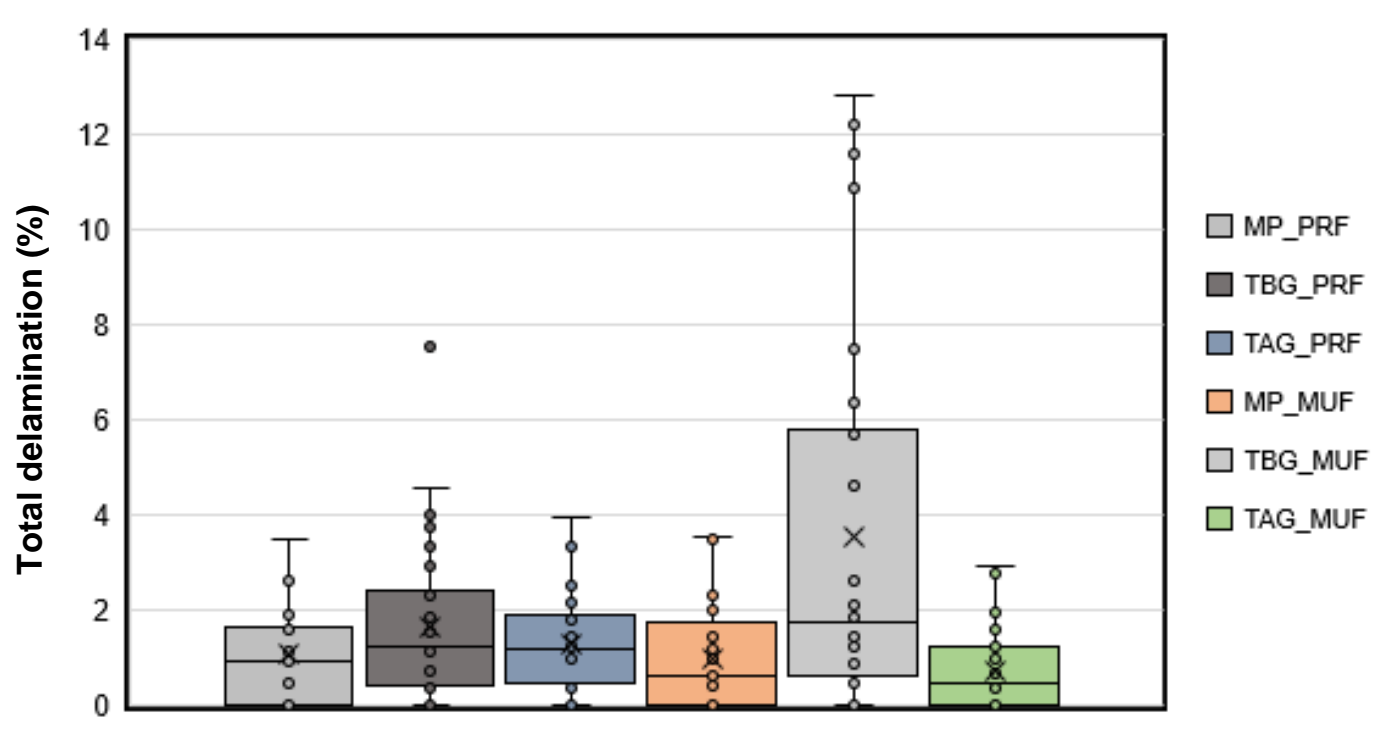

Fig. 2. Total delamination (\%) of each treatment set after the $3^{\text {rd }}$ test cycle

Considering the possible factors that could influence the delamination performance, the possible influence of density, moisture content, and other parameters related to gluing process was not considered. Most delaminations occurred in the glue lines whose adjacent lamellas presented growth rings displayed tangentially to the glue lines and wider compared to the lamellas of other elements (Fig. 3).
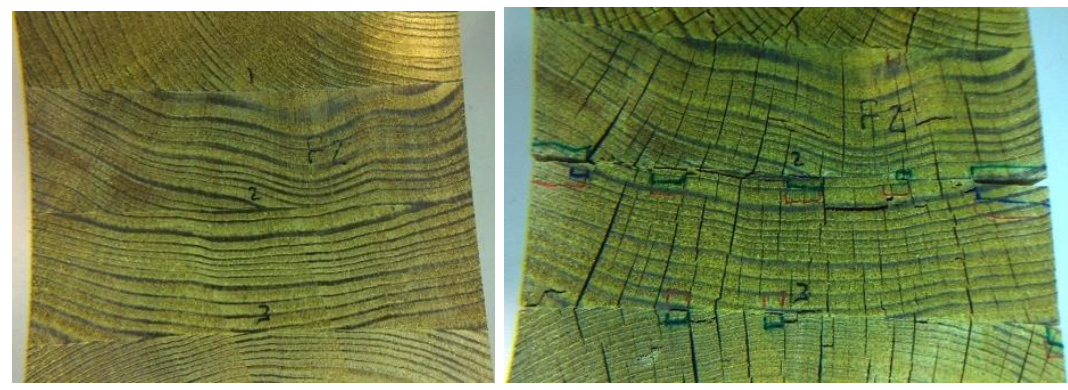

Fig. 3. Wide and tangential annual rings (left) and delamination occurred after the 3rd test cycle (right)

Table 4. Summary of Mean Shear Strength Test and WFP Results - PRF \& MUF

\begin{tabular}{|c|c|c|c|c|c|}
\hline \multirow{2}{*}{ PRF adhesive } & \multicolumn{3}{|c|}{ Glue line tests } & \multicolumn{2}{c|}{ Lamella tests } \\
\cline { 2 - 6 } & No. of tests & Shear strength (MPa) & Wood failure (\%) & $\begin{array}{c}\text { No. } \\
\text { of } \\
\text { tests }\end{array}$ & $\begin{array}{c}\text { Shear } \\
\text { strength } \\
\text { (MPa) }\end{array}$ \\
\hline MP & 89 & 13.53 & 95.28 & 48 & 13.89 \\
\hline TBG & 120 & 12.62 & 96.17 & 64 & 13.85 \\
\hline TAG & 119 & 11.35 & 95.83 & 64 & 12.04 \\
\hline \multirow{3}{*}{ MUF adhesive } & No. of tests & Shear strength (MPa) & Wood failure (\%) & $\begin{array}{c}\text { No. } \\
\text { of } \\
\text { tests }\end{array}$ & $\begin{array}{c}\text { Shear } \\
\text { strength } \\
\text { (MPa) }\end{array}$ \\
\hline MP & 90 & 13.77 & 96.61 & 48 & 13.27 \\
\hline TBG & 120 & 12.75 & 97.42 & 64 & 13.45 \\
\hline TAG & 120 & 11.73 & 98.08 & 64 & 13.23 \\
\hline
\end{tabular}


The shear strength and WFP results are presented in Table 4. All the specimens fulfilled the limits of WFP and shear strength established by EN 14080 (2013) (6 MPa with a minimum WFP of $90 \%$ for mean values). The best performance on shear strength of glue lines was found in the MP set for both adhesives. The application of a preservative treatment decreased shear strength wherever the phase which the treatment is applied; it was more considerable in TAG elements of both adhesives (16.1\% for PRF and $14.8 \%$ for MUF) in comparison to TBG elements (6.7\% for PRF and $7.4 \%$ for MUF). Regarding the shear strength of the lamellas, there was a relevant decrease only in TAG elements glued with PRF adhesive. This decrease was undoubetly influenced by the higher moisture content of the TAG_PRF_1 element specimen compared to the other sets. The mean values from WFP did not show considerable differences between the considered phases of preservative treatment.

\section{Exterior Analysis of Treated Elements}

The visual characterization of treated elements proposed in this work consisted of two different analysis: i) superficial delaminations after the drying process, and ii) the percentage of treatment in cross-section. During the drying process, the TAG elements exhibited some superficial delaminations in lateral glue lines, and their quantification was made by dividing the total length of the delaminations by the total length of the glue line. Regarding the superficial delamination the values varied between $1.08 \%$ and $6.23 \%$ for PRF adhesive and from $0.20 \%$ to $2.60 \%$ for MUF adhesive.

The analysis of the percentage of treatment in the cross-section (TAG and TBG elements) was made at the specimens obtained for delamination tests (prior testing). The percentage of cross-section without preservative treatment was then quantified in relation to the total area of the cross-section through the difference in colour. According to EN 3502 (1994), maritime pine heartwood is extremely difficult to treat and sapwood is easy to treat, which is a reason why part of the cross section from TAG and TBG elements did not receive preservative treatment (Fig. 4). From the external analysis of the boards used for MP and TAG elements, it was not possible to distinguish the presence of heartwood. In contrast, the TBG elements that were planed before gluing showed some untreated area.

The percentage of treatment in cross-section was determined through the mean values of the presence of treatment in the specimens collected from both ends of the elements. The presence of treatment was accounted by the percentage of treatment in crosssection, using the software AutoCad, where the total area of the cross-section was determined and divided by the area of treatment (green colour - Fig. 4) in cross-section.

This analysis demonstrated a considerable difference between the TBG_MUF elements (92\% of treatment in cross-section) and the remaining elements of TBG_PRF (44\% of treatment in cross-section) and TAG (48\% and $66 \%$ of treatment in cross-section, for MUF and PRF, respectively). Thus, the inadequate bonding performance found for TBG elements glued with MUF adhesive could be clearly related to the higher content of sapwood (preservative treatment area) within the cross-section compared with TBG elements glued with MUF adhesive and TAG (both adhesives).

Figure 4 presents two specimens showing the difference of retention of preservative product in TBG and TAG elements. The retention of treatment in TBG elements was mainly influenced by the presence of heartwood in its cross-section, identified by the contrast between the green colour of treated wood and the natural colour of the untreated wood area. The retention of treatment in TAG elements was influenced by the presence of heartwood and by the glue lines, which represented a barrier for treatment penetration. An 
example was the TAG element presented in Fig. 4 showing part of sapwood that did not receive treatment because of the heartwood presence and glue lines barriers.
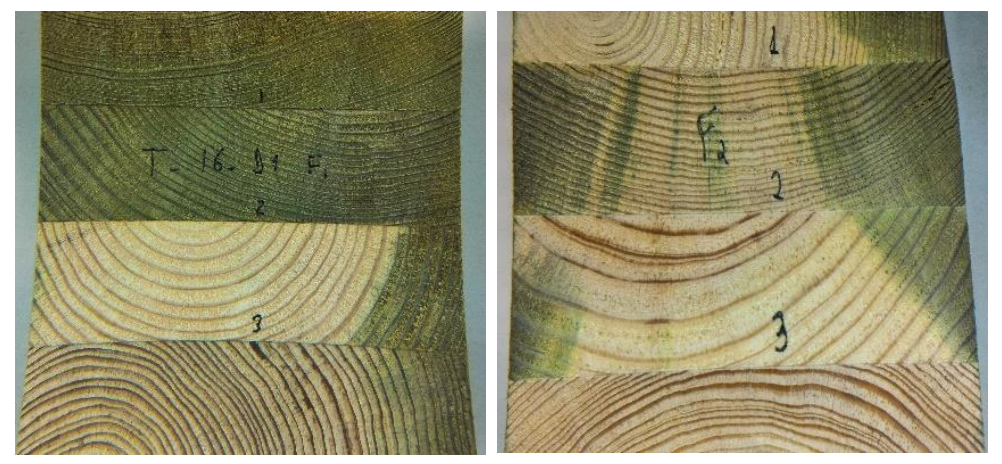

Fig. 4. TBG cross section after gluing (left) and TAG cross section after treatment (right)

Before delamination tests, the delaminations that result from the drying process in TAG elements were measured. From the 8 glulam elements belonging to TAG set, the initial delamination was residual with mean values ranging between $0.0 \%$ and $0.7 \%$ (TAG_PRF_1), which means that the drying process after the preservative treatment did not have a considerable influence on the glue lines.

\section{CONCLUSIONS}

1. In general, better performance in delamination was achieved with treated after gluing (TAG) elements compared with treated before gluing (TBG) elements, for which some specimens with excessive delamination were observed (melamine-urea-formaldehyde MUF elements).

2. The untreated elements (MP) glued with phenol-resorcinol-formaldehyde (PRF) had similar performance to the previous results obtained by Lampreia (2010).

3. The untreated elements (MP) glued with MUF presented good performance for both delamination and shear strength tests, which validates the glulam elements of maritime pine.

4. The shear strength of glue lines was affected by the preservative treatment, and it was more evident within the elements of TAG.

5. The selection of the boards to be used should have a full cross-section of sapwood to ensure an effective preservative treatment, especially for TAG elements, where the identification of sapwood is harder.

6. For TAG elements, the efficiency of a preservative treatment depends on the absence of heartwood on boards and on the glue lines that were considered barriers to the preservative product penetration.

7. The application of preservative treatment after bonding is followed by a drying process, which leads to superficial delaminations, cracks on lamellas and dimensional variations that could be considered a disadvantage compared to TBG elements.

8. The production of glulam with previously treated boards (TBG) has the inconvenient 
of generating a considerable amount of sawdust that contains the preservative product.

9. The authors recommend the analysis of the influence of glue lines on the treatment of timber after gluing (TAG) and the influence of sapwood and heartwood of glulam treatability as targets of future works.

\section{ACKNOWLEDGMENTS}

This work was financed by: FEDER funds through the Competitiveness Factors Operational Programme - COMPETE; national funds through FCT - Foundation for Science and Technology within the scope of the Project UIDB/04029/2020 - ISISE and the Project POCI-01-0145-FEDER-007633; and by the Regional Operational Programme for the Centro Region (Centro 2020) within the scope of the Project SUSpENsE CENTRO-01-0145-FEDER-000006.

The authors wish to thank Foundation for Science and Technology for the $\mathrm{PhD}$ grants (PD/BD/135159/2017) given to André Dias and (PD/BD/52656/2014) given to Carlos Martins in the frame of EcoCoRe doctoral programme, and to Dynea AS and Colquímica Adhesives for providing the adhesives and finally to Pedrosa Irmãos for the collaboration given with the raw material.

\section{REFERENCES CITED}

EN 14080 (2013). "Timber structures - Glued laminated timber and glued solid timber Requirements," European Committee for Standardization, Brussels.

EN 13183-1 (2002). "Moisture content of a piece of sawn timber - Part 1: Determination by oven dry method," European Committee for Standardization, Brussels.

Coggins, C. R. (2008). "Trends in timber preservation - A global perspective," Journal of Tropical Forest Science 20(4), 264-272.

Cruz, H. (1985). Application of Maritime Pine Species in Glulam Structures. Bonding Tests for External Environmental Conditions (in Portuguese). Report 267/85-NM, Laboratório Nacional de Engenharia Civil, Lisbon, Portugal.

Cruz, H., Martins, C., and Dias, A. M. P. G. (2018). "Structural gluing of Portuguese timbers," in: Timber: Bonds, Connections and Structures, G. Dill-Langer (ed.), University of Stuttgart - Material Testing Institute (MPA), Stuttgart, Germany, 171183

Franco da Costa, J. (1978). Application of Maritime Pine Species in Glued Structures. Bonding Feasibility (in Portuguese), Report - Proc. 33/11/6150, Laboratório Nacional de Engenharia Civil, Lisbon, Portugal.

Freeman, M. H., Shupe, T. F., Vlosky, R. and Barnes, H. M. (2003). "Past, present, and future of the wood preservation industry: Wood is a renewable natural resource that typically is preservative treated to ensure structural integrity in many exterior applications," Forest Products Journal 53(10), 8-15.

Gaspar, F., Cruz, H., Gomes, A., and Nunes, L. (2009). "Production of glued laminated timber with copper azole treated maritime pine," European Journal of Wood and Wood Products 68(2), 207-18. DOI: 10.1007/s00107-009-0373-6

Lampreia, N. (2010). Use of Adhesion Primers for Glued Laminated Timber Production 
with Maritime Pine (in Portuguese), Master's Thesis, Instituto Superior de Engenharia de Lisboa, Lisbon, Portugal.

Li, R., Cao, P., Xu, W., Ekevad, M., and Wang, X. A. (2018). "Experimental and numerical study of moisture-induced stress formation in hexagonal glulam using Xray computed tomography and finite-element analysis," BioResources 13(4), 73957403.

Lonza. (2020). "Lonzawoodprotection.com/eu/tanalith-family/." Retrieved $8^{\text {th }}$ January, 2020.

Lorenz, L., and Frihart, C. (2006). "Adhesive bonding of wood treated with ACQ and copper azole preservatives," Forest Products Journal 56(9), 90-93.

Miyazaki, J., and Nakano, T. (2003). "Effects of wood preservatives on adhesive properties- IV- Effects of preservation and incising on shear strength and delamination," Mokuzai Gakkaishi 49(3), 212-218.

Nunes, L., Carmo J., Vicente J., and Esteves B. (2016). "State of the art of industrial wood protection in Portugal," in: Proceedings of the 47th IRG Annual Meeting, Lisbon, Portugal, IRG/WP 16-30703, 1-7

Pontífice de Sousa, P. M. (1990). Structures of Glued Laminated Timber, Feasibility of using Maritime Pine (in Portuguese), Specialist Thesis - Proc. 083/11/9342, Laboratório Nacional de Engenharia Civil, Lisbon, Portugal.

Raknes, E. (1963). "Gluing of wood pressure-treated with water borne preservatives and flame retardants," Journal of the Institute of Wood Science 11, 24-44.

Selbo, M. L. (1957). "Laminating of preservative-treated wood," in: Proceedings of $A W P A$, Granbury, TX, USA, pp. 48-55.

Selbo, M. L. (1959). Summary of Information on Gluing of Treated Wood (Report No. 1785) (information reviewed and reaffirmed 1965), U.S. Department of Agriculture, Forest Products Laboratory, Madison, WI.

Silva, A. (2010). Analysis of Using Railway Sleepers Obtained from Glued Laminated Timber, as Alternative to Traditional Timber Railway Sleepers (in Portuguese), Master's Thesis, Instituto Superior de Engenharia de Lisboa, Lisbon, Portugal.

Truax, T. R., Blew, J. O., and Selbo, M. L. (1953). "Production of preservative treated Laminated timbers," in: Proceedings of AWPA, Granbury, TX, USA, pp. 113-123.

U.S. Department of Agriculture (USDA) (2010). Wood Handbook: Wood as an Engineering Material (General Technical Report FPL-GTR-190), U.S. Department of Agriculture, Forest Products Laboratory, Madison, WI.

Vick, C. B. (1995). Coupling agent improves durability of PRF bonds to CCA-treated southern pine," Forest Products Journal 45(3), 78-84.

Vick, C. B. (1997). "Enhanced adhesion of melamine-urea and melamine adhesives to CCA-treated southern pine lumber," Forest Products Journal 47(7-8), 83-87.

Article submitted: February 24, 2020; Peer review completed: April 26, 2020; Revised version received and accepted: May 30, 2020; Published: June 3, 2020.

DOI: $10.15376 /$ biores.15.3.5725-5736 